\title{
Symphysis-fundal height at term: A new birth weight predictive equation
}

\author{
Alessandra Curti, Margherita Zanello, Silvia Battistini, Diana Cabassi, Gabriella Cangini, \\ Natalia Dini, Cristina Giovannini, Vincenza Leccese, Stefania Piersimoni, Nadia Rimondi and \\ Antonio Farina* \\ Department of Medicine and Surgery DIMEC-Division of Prenatal Medicine St. Orsola Malpighi Hospital, University of \\ Bologna, Bologna, Italy. \\ Accepted 19 September, 2013

\begin{abstract}
There is clinical utility in having a simple and low-cost method of predicting birth weight. To identify abnormal fetal growth, in fact, can reduce the risk of adverse perinatal outcomes. A longitudinal observational cohort study, including 1034 low-risk singleton pregnancies at term, was performed at the Division of Prenatal Medicine, St. Orsola-Malpighi Hospital, University of Bologna, Bologna (Italy) to derive a reliable equation based on maternal characteristics. The following formula was obtained: estimated birth weight $(\mathrm{g})=1485.61+($ symphysis-fundal height $(\mathrm{cm}) \times 23.37)+(11.62 \mathrm{~cm} \times$ maternal abdominal circumference) + [body mass index $(B M I) \times(-6.81)]+($ parity $(0=$ nulliparous, $1=$ multiparous $)$ $\times 72.25$ ). Based on study results, $92 \%$ of the estimated weights were within the $10 \%$ of the actual weight at delivery. The role of obstetric and maternal factors in term birth weight prediction is, therefore, confirmed. Prospective estimations are needed to validate the model proposed.
\end{abstract}

Key words: Symphysis-fundal height, multivariable birth weight prediction, term of pregnancy.

\section{INTRODUCTION}

Birth weight prediction is always challenging. Estimating fetal weight at term helps to determine management of pregnancy during the labor. Both macrosomic and intrauterine growth restricted fetuses would benefit from a proper evaluation of the weight that can significantly reduce the risk of neonatal and maternal complications.

Ultrasound, if performed at term, is reported to properly estimate neonatal weight within $10 \%$ in 55 to $75 \%$ of cases (Chauhan, 1993, 1998; Shamley, 1994; Barnhard, 1996; Hall, 1996; Sherman, 1998; Baum, 2002; Noumi, 2005), but this technique is considered expensive and it is not always available in labour ward. There is, therefore, clinical utility in having a simple and low-cost method of predicting term birth weight in order to identify abnormal fetal growth and to reduce the risk of adverse perinatal outcomes.
Although there is insufficient evidence to determine whether symphysis-fundal height (SFH) measurement is effective in detecting abnormal growth (Robert, 2012), this measurement is performed in many countries to estimate fetal weight (Gardosi, 1999; Steingrimsdottir, 1995; Peregrine, 2007).

Moreover, one recent approach to birth weight prediction is based upon a quantitative assessment of maternal characteristics and pregnancy-specific factors, such as gestational age at delivery, maternal height and weight, third-trimester weight gain rate, parity and fetal gender. In a recent study, a function of these six variables was reported to estimate term birth weight in Caucasian as accurately as ultrasound fetal biometry (Barnhard, 1996; Fuchs, 2013).

The aim of the present study was to derive a reliable 
Table 1. Demographic characteristics of study population (data expressed in percentage or mean \pm standard deviation (SD)).

\begin{tabular}{lc}
\hline Characteristic & Study population $(\mathbf{n}=\mathbf{1 0 3 4})$ \\
\hline Percentage of nulliparous & 68.4 \\
Percentage of male fetuses & 48.9 \\
Maternal age (years) & $33.2 \pm 5.42$ \\
$\mathrm{SFH}^{*}(\mathrm{~cm})$ & $36.6 \pm 2.73$ \\
$\mathrm{mAC}(\mathrm{cm})$ & $107.3 \pm 8.08$ \\
$\mathrm{BMI}\left(\mathrm{kg} / \mathrm{m}^{2}\right)$ & $27.7 \pm 4.1$ \\
$\mathrm{Gestational}$ age at estimation (days) & $281 \pm 2.97$ \\
EFW*** by GLM $(\mathrm{g})$ & $3420 \pm 126$ \\
Neonatal Weight $(\mathrm{g})$ & $3420 \pm 335$ \\
Time between estimation and birth (days) & $6 \pm 4.37$ \\
\hline
\end{tabular}

*SFH: Symphysis-fundal height; ${ }^{* *} \mathrm{mAC}$ : maternal abdominal circumference; ${ }^{* *} \mathrm{EFW}$ : estimated fetal weight.

equation based on maternal characteristics, including $\mathrm{SFH}$, to predict birth weight at term.

\section{MATERIALS AND METHODS}

This was a longitudinal observational cohort study performed at the Division of Prenatal Medicine, St. Orsola-Malpighi Hospital, University of Bologna, Bologna (Italy). Caucasian women over eighteen years old with low risk singleton pregnancies between $38+0$ and $40+6$ weeks' gestation were included. Maternal chronic diseases were excluded that could affect the neonatal weight (e.g. metabolic diseases or chronic hypertension) and conditions that could alter uterine volume (e.g. uterine fibroids), as well as neonates with birth weight less than $2500 \mathrm{~g}$ or greater than $4000 \mathrm{~g}$.

At the time of recruitment, clinical data were collected, including maternal weight and height (to calculate body mass index (BMI), $\mathrm{kg} / \mathrm{m}^{2}$ ), parity, and gestational age. SFH was recorded in each case. Measurement was performed from the top of symphysis pubis to the highest part of the uterus, using a non-elastic tape measure, while women lied in supine position with empty urinary bladder. Maternal abdominal circumference (mAC) was recorded in the point of maximal diameter, as well. Each measurement was reported in centimetres.

Statistical analysis was performed with Statistical Package for Social sciences (SPSS) software version 11.00 (SPSS Inc., Chicago, II, USA). Descriptive analysis was performed by parametric statistics. A general linear model (GLM) was used to identify the most accurate birth weight prediction equation. Analysis of predictors was realized with the multivariable evaluation of coefficients associated to each one. Multivariable weight estimation was plotted versus the neonatal weight at the time of delivery through analysis if residuals, and the residual of weight estimation were plotted against the week + days of delivery.

\section{RESULTS}

Between January and November, 2012, 1034 patients were included in the study. Demographic characteristics of the study population are depicted in Table 1.

Results of GLM are shown in Table 2 and Figure 1. The following equation was derived: estimated fetal weight $(g)=1485.61+(\mathrm{SFH} \times 23.37)+(\mathrm{mAC} \times 11.62)+$
[BMI $\times(6.81)]+($ Parity $(0=$ nulliparous, $1=$ multiparous $)$ $\times 72.25) .\left(R^{2}=0.242, F=329.7, p\right.$-value $\left.<0.001\right)$.

Figure 2 reports the results of residual analysis of estimated fetal weight plotted versus gestational age (days) at delivery. A symmetrical mean error of -50 to $+50 \mathrm{~g}$ was quoted, passing for $0 \mathrm{~g}$ at 280 days of gestational age. However, this effect was considered not significant $\left(R^{2}=0.002, F=2.32\right.$, p-value $\left.=0.128\right)$, even if the extreme bounds of the graphics range from -500 to $+500 \mathrm{~g}$.

\section{DISCUSSION}

The present study aimed to test the retrospective accuracy in the prediction of birth weight of a new multivariable equation derived by SFH measurement and using maternal characteristics. Based on our results, the derived equation can properly retrospectively estimate the neonatal weight at term. The quoted GLM yielded, in fact, a concordance within the $10 \%$ of actual weight of $92 \%$.

SFH measurement is a simple and inexpensive method to detect abnormal fetal growth; however, according to a recent systematic review, there is not enough evidence to evaluate the use of this technique in the routine antenatal care (Robert, 2012). Nonetheless, the combination with other factors, such as gestational age at delivery, maternal height and weight, third-trimester weight gain rate, parity and fetal gender seems to increase the accuracy to within \pm 7.6 to $8.7 \%$ of actual birth weight ( \pm 267 to $296 \mathrm{~g}$ ), similar to the best reported values for ultrasound fetal biometry (Gardosi, 1999; Nahum, 1999; Kayem, 2009). A multicentre study evaluated the diagnostic value of SFH (plus a series of obstetrical factors, including parity, presentation and fetal gender) between 37 and 41 weeks' gestation (Kayem, 2009). $\mathrm{SFH}$ is associated with $61.6 \%$ of correct prediction within $10 \%$, reaching a sensitivity of 40 and $45 \%$ for low and high birth weight, respectively. Moreover, Buchmann et 
Table 2. Results of retrospective GLM (Dependent variable: neonatal weight)

\begin{tabular}{|c|c|c|c|c|c|c|c|}
\hline \multirow{2}{*}{ Independent variable } & \multirow{2}{*}{$\beta$} & \multirow{2}{*}{ SE } & \multirow{2}{*}{$\mathbf{t}$} & \multirow{2}{*}{$p$-value } & \multicolumn{2}{|c|}{ Confidence interval 95\% } & \multirow{2}{*}{ Observed power (\%) } \\
\hline & & & & & Lower bound & Upper bound & \\
\hline Intercept & 1485.61 & 158.40 & 9.38 & $<0.001$ & 1174.78 & 1796.43 & 1.00 \\
\hline SFH & 23.37 & 3.88 & 6.03 & $<0.001$ & 15.76 & 30.97 & 1.00 \\
\hline $\mathrm{mAC}$ & 11.62 & 1.75 & 6.62 & $<0.001$ & 8.17 & 15.06 & 1.00 \\
\hline $\mathrm{BMI}$ & -6.81 & 3.29 & -2.07 & 0.039 & -13.28 & 0.35 & 0.54 \\
\hline Parity & 72.25 & 20.97 & 3.45 & 0.001 & 31.11 & 113.39 & 0.93 \\
\hline
\end{tabular}

$a=$ At a type I error=0.05; $\beta=$ Regression coefficient; $S E=$ Standard error; $t=t$-statistics $(\beta / S E) ; p$-value was considered significant if $<0.05$.

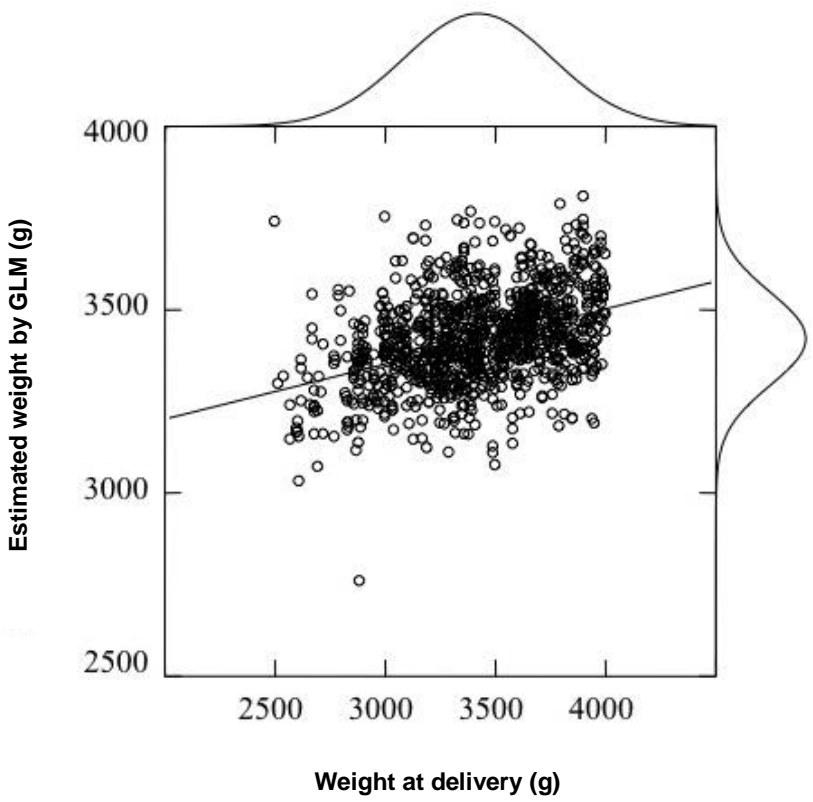

Figure 1. Correlation between estimated weight by GLM and actual weight at birth.

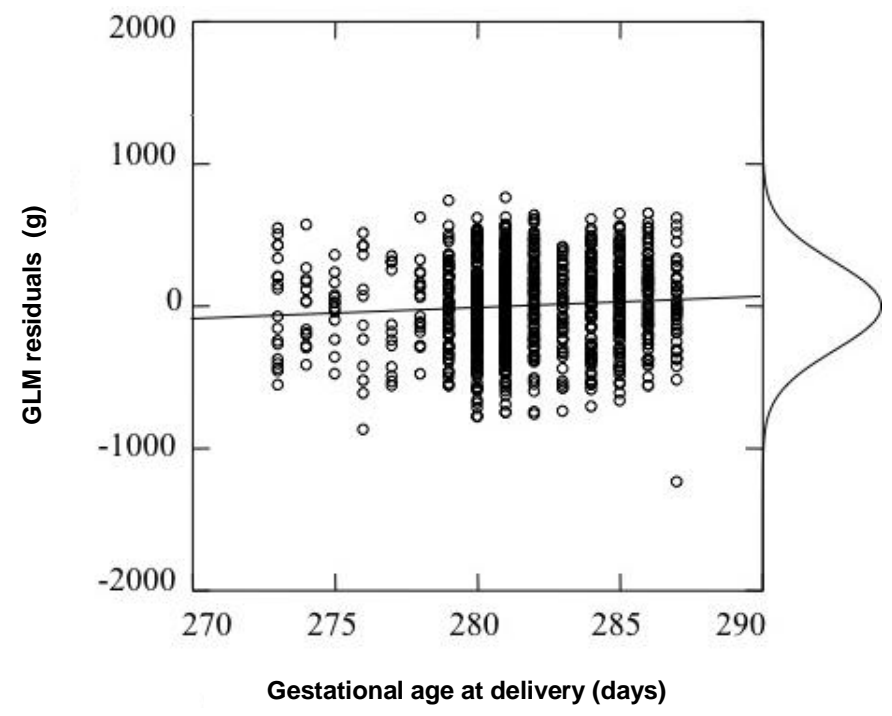

Figure 2. Distribution of the residuals versus days at delivery. al. (2009) shows that a SFH $>40 \mathrm{~cm}$ can detect $82 \%$ of macrosomic neonates (prediction within $10 \%$ of actual weight of $68.1 \%$ ).

Our results are consistent with available literature. There are, however, some limitations to their interpretation. The derived formula has been designed only for estimation at term of pregnancy and becomes unreliable at the extremes of birth weights since it includes only normal weights infants. Therefore, it must be considered just as a preliminary analysis to test if those selected variable have a consistent predictive power of birth weight. It is reasonable that the same panels of variables would properly work in macrosomic and/or intrauterine growth restricted fetuses, as well.

According to our study, the role of obstetric and maternal factors in birth weight prediction at term of pregnancy is confirmed, but a prospective study in necessary to confirm the efficacy of the equation fitted by using the data enrolled in this study. If confirmed, the value of the variables used to build up the statistical algorithm is higher to clinical estimation performed in labor by an expert obstetrician (Chauhan, 1993, 1998; Shamley, 1994; Barnhard, 1996; Hall, 1996; Sherman, 1998; Baum, 2002; Noumi, 2005).

\section{REFERENCES}

Barnhard Y, Bar-Hava I, Divon MY (1996). Accuracy of intrapartum estimates of fetal weight. Effect of oligohydramnios. J. Reprod. Med. 41:907-910.

Baum JD, Gussman D, Wirth JC (2002). Clinical and patient estimation of fetal weight vs. ultrasound examination. J. Reprod. Med. 47:194198.

Buchmann E, Tlale K (2009). Simple clinical formula for predicting fetal weight in labour at term--derivation and validation. S. Afr. Med J. 99(6):457-60.

Chauhan SP, Lutton TC, Bailey KJ, Morrison JC (1993). Intrapartum prediction of birth weight: clinical versus sonographic estimation based on femur length alone. Obstet Gynecol 81:695-697.

Chauhan SP, Hendrix NW, Magann EF, Morrison JC, Kenney SP, Devoe LD (1998). Limitations of clinical and sonographic estimates of birth weight: experience with 1034 parturients. Obstet. Gynecol. 91:72-77.

Fuchs F, Bouyer J, Rozenberg P, Senat MV (2013). Adverse maternal outcomes associated with fetal macrosomia: what are the risk factors beyond birthweight? BMC Pregnancy Childbirth. 8:13:90.

Gardosi J, Francis A (1999). Controlled trial of fundal height measurement plotted on customised antenatal growth charts. Bra. J. Obstet. Gynaecol. 106:309-317. 
Hall MH (1996). Guessing the weight of the baby. Br. J. Obstet. Gynaecol.103: 734-736.

Kayem G, Grangé G, Bréart G, Goffinet F (2009). Comparison of fundal height measurement and sonographically measured fetal abdominal circumference in the prediction of high and low birth weight at term. Ultrasound Obstet. Gynecol. 34(5): 566-71.

Nahum GG, Stanislaw H, Huffaker BJ (1999). Accurate prediction of term birth weight from prospectively measurable maternal characteristics. J. Reprod. Med. 44:705-12.

Noumi G, Collado-Khoury F, Bombard A, Julliard K, Weiner Z (2005). Clinical and sonographic estimation of fetal weight performed during labor by residents. Am. J. Obstet. Gynecol. 192:1407-1409

Peregrine E, O'Brien P, Jauniaux E (2007). Clinical and ultrasound estimation of birth weight prior to induction of labor at term. Ultrasound Obstet. Gynecol. 29:304-309.

Robert PJ, Ho JJ, Valliapan J, Sivasangari S (2012) Symphysial fundal height (SFH) measurement in pregnancy for detecting abnormal fetal growth, Cochrane Database Syst. Rev. 7:CD008136.
Steingrimsdottir T, Cnattingius S, Lindmark G (1995). Symphysisfundus height: construction of a new Swedish reference curve, based on ultrasonically dated pregnancies. Acta Obstet Gynecol Scand 74: 346-351.

Shamley KT, Landon MB (1994). Accuracy and modifying factors for ultrasonographic determination of fetal weight at term. Obstet Gynecol. 84:926-930.

Sherman DJ, Arieli S, Tovbin J, Siegel G, Caspi E, Bukovsky I (1998). comparison of clinical and ultrasonic estimation of fetal weight. Obstet. Gynecol. 91:212-217. 